\title{
Thermal degradation of crab shell biomass, a nitrogen-containing carbon precursor
}

\author{
Zoltán Sebestyén $^{1} \cdot$ Emma Jakab $^{1} \cdot$ Andrea Domán $^{2} \cdot$ Péter Bokrossy $^{2} \cdot$ Imre Bertóti $^{1} \cdot$ János Madarász $^{3}$. \\ Krisztina László ${ }^{2}$ (1)
}

Received: 3 September 2019 / Accepted: 11 February 2020 / Published online: 2 March 2020

(C) The Author(s) 2020

\begin{abstract}
Waste and low-cost lignocellulosic biomasses are well studied and widely used as raw materials for porous carbon adsorbents. Much less attention is given to the exploration of the potential of marine biomasses, though these materials contain also nitrogen, which -if preserved during the processing — has a beneficial influence on the sorption properties of the porous carbon obtained. Here, we report a multi-technique investigation into the conversion of crab shell to porous carbon adsorbent. Thermogravimetry and pyrolysis-GC/MS studies were used to reveal the thermal degradation of this natural polymer and follow the decomposition process through the identification of the products. Almost 40 various volatile degradation products were distinguished released at $500{ }^{\circ} \mathrm{C}$ pyrolysis temperature. Based on the TGA/DTG results, two temperatures, 350 and $500{ }^{\circ} \mathrm{C}$, were selected to obtain pyrolytic samples in macroscopic quantities in order to characterize the morphology and surface chemistry of the solid fraction. More than $50 \%$ of the nitrogen atoms were still in the carbonaceous matrix after the $500{ }^{\circ} \mathrm{C}$ pyrolysis in the $\mathrm{C}-\mathrm{N}=\mathrm{C}, \mathrm{C}-\mathrm{NH}$ and $3 \mathrm{C}-\mathrm{N}$-type bonds. The ash content $<1 \%$ included hydroxylapatite-type crystalline matter. Based on these results, we may conclude that crab shells have a high potential as precursor of nitrogen-containing biochar.
\end{abstract}

Keywords Marine biomass · Crab shell $\cdot$ Thermal decomposition · Pyrolysis-gas chromatography/mass spectrometry

\section{Introduction}

The continuously growing demand by the water treatment and energy sectors for carbon materials calls for new carbon sources $[1,2]$. An obvious solution is the sustainable source represented by the renewable biomass. The estimated carbon content in the overall biomass composition of the biosphere is $\approx 550$ gigatons and is distributed among all of the segments of life [3]. While biomass of terrestrial lignocellulosic origin has been considered as raw materials for long, the

Krisztina László

klaszlo@mail.bme.hu

1 Institute of Materials and Environmental Chemistry, Research Centre for Natural Sciences, Magyar tudósok körútja 2, Budapest 1117, Hungary

2 Department of Physical Chemistry and Materials Science, Budapest University of Technology and Economics, Budapest 1521, Hungary

3 Department of Inorganic and Analytical Chemistry, Budapest University of Technology and Economics, Budapest 1521, Hungary potential of the enormous amount of marine biomass is far from being fully explored $[4,5]$. Food processing industry produces $6-8$ million tonnes of crab, lobster and shrimp shells worldwide on a yearly basis and, as their potential value is ignored, most typically end up in landfills [6]. The crustacean waste from crab shells, etc. is rich in chitin and inorganic components, such as $\mathrm{CaCO}_{3}$, silica and phosphates providing numerous options for being converted to substantially more valuable products. Even their use as natural biosorbents was reported to be effective for the removal of heavy metals from wastewater [7]. They are often used as chitosan to be used in composites or anti-corrosive layers $[8,9]$. Chitosan can be processed in enzymatic conditions [10] or in acidic aqueous medium. The latter, with the help of microwave treatment, may provide such valuable platform molecules like levulinic acid [11]. In materials science, they could serve as templates for nanostructures, carbon source for high value or precursors for a calcium-rich biochar [12]. The conversion to porous carbon, also to biochars, is most often performed by thermal (e.g., pyrolytic, microwave assisted) or hydrothermal treatments [13-15]. Marine biomass such as algae $[16,17]$ and crab shell $[12,13]$ can only 
be contemplated as green precursor if its upgrading to more valued products takes place in a conservational, green way as well. Therefore, here we focus on the pyrolytic route in order to reveal the thermal fractionation and the intermediates formed during the thermal transition of this biomass. The thermal decomposition of lignocellulosic biomass has been widely studied [18-20]; however, the utilization of marine biomass by pyrolysis [21] received much less attention. Understanding the pyrolytic process helps to optimize the macroscopic pyrolysis in a way that the nitrogen content of the crab shells can be at least partially retained in the product. Nitrogen, already at low concentration (1-1.5\%), affects the physico-chemical behavior of carbons by perturbing the electron distribution. Due to their electron donor character, they also enhance the uptake of acidic gases and the adsorption capacities toward heavy metal ions [22, 23]. Nitrogen functionalities on porous carbon surfaces also have an important role in (electro)catalytic reactions [24].

\section{Materials and methods}

\section{Materials and their characterization}

As-received crab shell flakes were used for these studies. The raw material was analyzed by elemental analysis using Vario EL III instrument (Elementar Analysensysteme $\mathrm{GmbH}$, Germany) in carbon, nitrogen and hydrogen modes. Chars were prepared in a static macroscopic pyrolytic process. Based on the thermogravimetric results, samples were obtained at 350 and $500{ }^{\circ} \mathrm{C}$ in dried argon flow $\left(4 \mathrm{dm}^{3} \mathrm{~h}^{-1}\right.$, heating rate $5{ }^{\circ} \mathrm{C} \mathrm{min}^{-1}$, hold for $30 \mathrm{~min}$ ) and labeled as $\mathrm{C} 350$ and C500, respectively. The precursor biomass as well as C350 and C500 was characterized by scanning electron microscopy (SEM), powder X-ray diffraction (XRD) and $\mathrm{X}$-ray photoelectron spectroscopy (XPS). The microscopic images were taken by a JEOL JSM 6380LA (JEOL, Tokyo, Japan) instrument. X-ray diffractograms were recorded with a copper anode diffractometer (X'pert Pro MPD, PANalytical Bv., The Netherlands) using a 'zero-background Si-single crystal' sample holder. Phase identification was assisted by the Search Match algorithm of High Score Plus (PANalytical Bv.) software, based on the international Powder Diffraction File (PDF4+, Release 2019, International Centre of Diffraction Data, ICDD, Pennsylvania, USA). Photoelectron spectra were obtained on a Kratos XSAM 800 spectrometer (UK) operating in fixed analyzer transmission mode, $\mathrm{Mg} \mathrm{K} \alpha_{1,2}$ $(1253.6 \mathrm{eV})$ excitation. Spectra were acquired and processed by the Kratos Vision 2 software package. The assignment of the chemical states is based on the information given in the Supplement of [25].

\section{Thermogravimetric analysis (TGA)}

The thermal behavior of crab shell biomass was analyzed by a modified thermobalance (PerkinElmer TGS-2, USA). Approximately $3 \mathrm{mg}$ crab shell sample was measured under an argon atmosphere at a flow rate of $140 \mathrm{~cm}^{3} \mathrm{~min}^{-1}$. The sample was heated at a rate of $20{ }^{\circ} \mathrm{C} \mathrm{min}-1$ from 25 to $900{ }^{\circ} \mathrm{C}$ in a platinum sample pan. The carbonaceous residue was heated in a synthetic air atmosphere at a heating rate of $10{ }^{\circ} \mathrm{C} \mathrm{min}{ }^{-1}$ from 25 to $900{ }^{\circ} \mathrm{C}$. To avoid the ignition of the carbonaceous residue, lower heating rate was applied in oxidative atmosphere than in argon.

\section{Pyrolysis-gas chromatography/mass spectrometry (Py-GC/MS)}

Approximately $0.5 \mathrm{mg}$ crab shell biomass sample was pyrolyzed at 320 and $500{ }^{\circ} \mathrm{C}$ for $20 \mathrm{~s}$ in a helium atmosphere using a Pyroprobe 2000 (USA) pyrolyzer interfaced to an Agilent 6890A/5973 GC/MS (USA). The interface and the GC injector were heated to $280{ }^{\circ} \mathrm{C}$. The injector was operated in a split mode with the split ratio of 1:20. The pyrolysis products were separated on a DB-1701 capillary column $(30 \mathrm{~m} \times 0.25 \mathrm{~mm}, 0.25 \mu \mathrm{m}$ film thickness). The $\mathrm{GC}$ oven was programmed to hold at $40{ }^{\circ} \mathrm{C}$ for $4 \mathrm{~min}$, and then increase the temperature at a rate of $6{ }^{\circ} \mathrm{C} \mathrm{min}{ }^{-1}$ to $280{ }^{\circ} \mathrm{C}$ (hold for $10 \mathrm{~min}$ ). The mass range of $\mathrm{m} / \mathrm{z}, 14-500$ was scanned by the mass spectrometer in electron impact mode at $70 \mathrm{eV}$ electron energy. The identification of the molecules was based on NIST 2011 mass spectral library. Three replicates were carried out at both pyrolysis temperatures.

\section{Results and discussion}

\section{Characterization of the samples}

The apparent and matrix densities of the precursor flakes were 0.075 and $1.32 \mathrm{~g} \mathrm{~cm}^{-3}$, respectively. Based on the elemental analysis, the crab shell contained $43.8 \%$ carbon, $6.2 \%$ nitrogen and $6.7 \%$ hydrogen, leaving more than $43 \%$ for oxygen and the ash content. From independent measurement, the latter was only $0.69 \%$ (sample size $>1 \mathrm{~g}, 16 \mathrm{~h}$, $600{ }^{\circ} \mathrm{C}$ in air). The low ash content was also confirmed by the TGA measurement in synthetic air. Based on XRD, the ash contains hydroxylapatite-type crystalline matter $\left[\mathrm{Ca}_{5}\left(\mathrm{PO}_{4}\right)_{3} \mathrm{OH}\right]$. The ash, and consequently the Ca content, is certainly below the values reported by Dai et al. [12] and in different chemical forms like in the sample used for an in situ templating by Gao et al. [26]. 

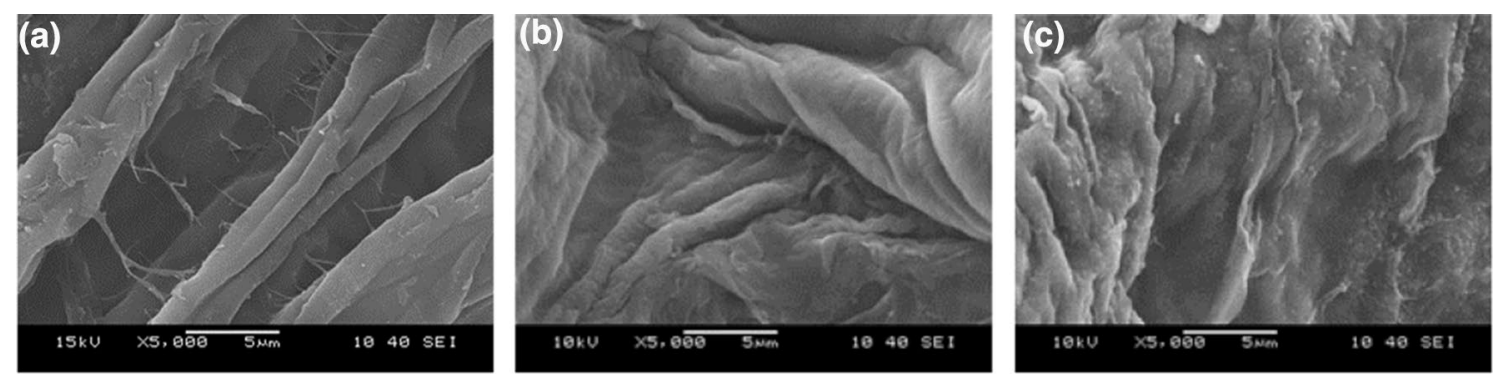

Fig. 1 SEM images of the precursor (a), C350 (b) and C500 (c) samples

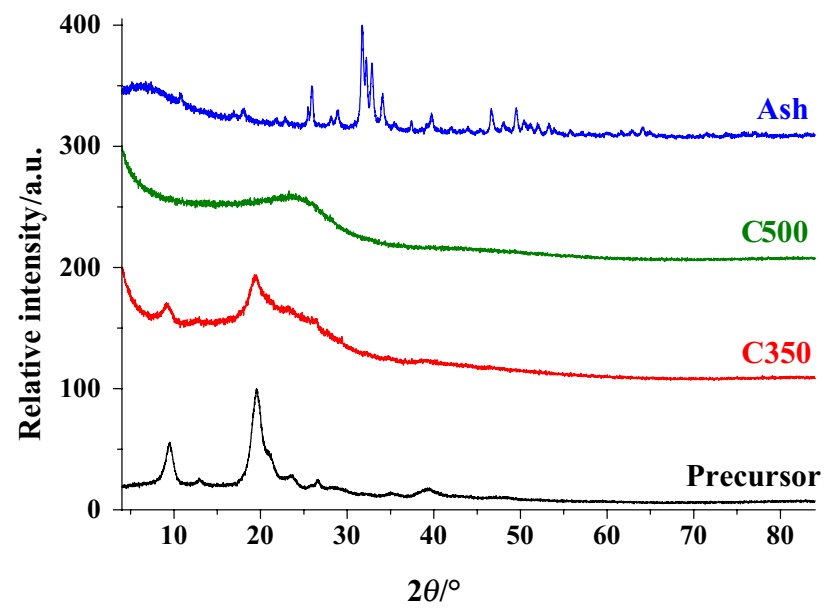

Fig. 2 Powder X-ray diffractograms of the precursor, the pyrolyzed $\mathrm{C} 350, \mathrm{C} 500$ samples and the ash remained at $600{ }^{\circ} \mathrm{C}$

According to Fig. 1 the integrity of the matrix is retained after the pyrolytic treatments in spite of the respective 30 and $24 \%$ yield at 350 and $500{ }^{\circ} \mathrm{C}$. XRD, however, revealed that the orthorhombically ordered chitin (poly ( $N$-acetyl- $\beta$ D-glucosamine), $\left.\left(\mathrm{C}_{8} \mathrm{H}_{13} \mathrm{O}_{5} \mathrm{~N}\right)_{\mathrm{n}}\right)$ structure [27] of the biopolymer gradually disappeared (Fig. 2). The appearing lowintensity hump above $2 \theta=20^{\circ}$ indicates the presence of a developing colloidal size layered carbon structure as seen in the case of several precursors [28]. The small amount of the inorganic impurities does not allow the identification of the calcium compound in the crab shell itself.

The residual nitrogen- and oxygen-containing groups may play significant roles in determining the properties of the chars. Therefore, XPS technique was applied that provides important information on the elemental composition and the chemical state of the atoms present on the surface of the material. Results of the XPS analysis of the crab shell samples show that the alteration of the oxygen content is the most significant (presented in Table 1) during pyrolysis. Similar changes were observed by Wang et al. in the case of seaweed sample [21]. Indeed, it is shown in Table 2 that the majority of the released compounds
Table 1 Results of the XPS analysis. Surface composition of the crab shell and the pyrolyzed samples and the distribution of the identified species

\begin{tabular}{|c|c|c|c|c|c|}
\hline Assignation & Energy/eV & $\begin{array}{l}\text { Chemical } \\
\text { state }^{\mathrm{a}}\end{array}$ & Precursor & $\mathrm{C} 350$ & C500 \\
\hline Total $O$, at $\%$ & & & 25.6 & 14.9 & 10.7 \\
\hline $\mathrm{O} 1$ & 530.9 & $\mathrm{O}=\mathrm{C}$ & 7.2 & 7.3 & 6.4 \\
\hline $\mathrm{O} 2$ & 532.3 & $\mathrm{O}-\mathrm{C}$ & 13.6 & 4.8 & 2.2 \\
\hline $\mathrm{O} 3$ & 533.6 & $\mathrm{O}-\mathrm{C}=\mathrm{O}$ & 4.8 & 2.5 & 2 \\
\hline Total $N$, at $\%$ & & & 6.4 & 8.1 & 8.2 \\
\hline N1 & 398.3 & $\mathrm{C}-\mathrm{N}=\mathrm{C}$ & 0.2 & 0.7 & 1.7 \\
\hline $\mathrm{N} 2$ & 399.5 & $\mathrm{C}-\mathrm{NH}$ & 5.4 & 3.4 & 2.6 \\
\hline $\mathrm{N} 3$ & 400.7 & $3 \mathrm{C}-\mathrm{N}$ & 0.6 & 3.6 & 3.3 \\
\hline Total C, at \% & & & 66.5 & 74.8 & 78.1 \\
\hline $\mathrm{C} 1$ & 284.7 & $\mathrm{C}-\mathrm{C}$ & 37 & 41.3 & 54.6 \\
\hline $\mathrm{C} 2$ & 286.3 & $\mathrm{C}-\mathrm{O}$ & 20.2 & 20.7 & 13.6 \\
\hline $\mathrm{C} 3$ & 287.9 & $\mathrm{C}=\mathrm{O}$ & 9.4 & 7.4 & 5 \\
\hline $\mathrm{C} 4$ & 289.1 & $\mathrm{C}=\mathrm{OOH}$ & 0.1 & 4.3 & 3.6 \\
\hline Csat & 291.5 & $\mathrm{C} \pi-\pi^{\mathrm{a}}$ & 0 & 2.1 & 2.2 \\
\hline $\mathrm{Ca}$ & 350.4 & $\mathrm{Ca}-\mathrm{O}$ & 0.9 & 1.3 & 1.7 \\
\hline $\mathrm{P}$ & 132.8 & $\mathrm{P}-\mathrm{O} 4$ & 0.5 & 0.8 & 1.1 \\
\hline
\end{tabular}

The italics numbers refer to the sum of the identified species of $\mathrm{O}, \mathrm{N}$, and $\mathrm{C}$ atoms

${ }^{\mathrm{a}}$ For the assignment of the chemical states, see the Supplement of [25]

contain oxygen. During the degradation of the precursor, $\mathrm{C}-\mathrm{N}$ species might be released as well, in spite of the slight increase in the $\mathrm{N}$-content of the carbonized samples. The Si content of the crab shell, if any, was below the detection limit of this technique. The $\mathrm{Ca} / \mathrm{P}$ atomic ratio, close to 1.5 , implies on average a $\mathrm{Ca}_{3}\left(\mathrm{PO}_{4}\right)_{2}$-type compound in the precursor flakes. Although it is slightly below the $\mathrm{Ca} / \mathrm{P}$ ratio in hydroxylapatite (1.66), this difference is may be due to the well-known fact that natural materials typically contain a mixture of various phosphates. If we presume that no volatile $\mathrm{Ca}$ and $\mathrm{P}$ compounds form during the pyrolysis (as confirmed by the Py-GC/MS analysis below), the relative N/P intensity data indicate that 84 and $59 \%$ of the initial $\mathrm{N}$-content is retained in the 
Table 2 The main decomposition products released in the Py-GC/MS experiments from crab shell biomass. Peak numbers refer to Fig. 4

\begin{tabular}{|c|c|c|c|c|}
\hline Peak \# & Ret. time/min & Compounds & Characteristic MS ions $\mathrm{m} / \mathrm{z}$ & $\mathrm{M} / \mathrm{g} \mathrm{mol}^{-1}$ \\
\hline \multirow[t]{4}{*}{1} & \multirow[t]{4}{*}{$2.07-2.28$} & Carbon dioxide & 44,28 & 44 \\
\hline & & Water & 18,17 & 18 \\
\hline & & Methyl iodide & 142,127 & 142 \\
\hline & & Acetonitrile & $41,40,39$ & 41 \\
\hline 2 & 3.81 & Hydroxyacetaldehyde & $31,32,60$ & 60 \\
\hline 3 & 4.74 & Acetic acid & $43,45,60$ & 60 \\
\hline 4 & 8.28 & 3-Hydroxypropanal & $43,73,74$ & 74 \\
\hline 5 & 11.31 & Acetamide & $59,44,43$ & 59 \\
\hline 6 & 12.62 & 2-Pyridinaldehyde & $79,52,107$ & 107 \\
\hline 7 & 14.30 & Unidentified $+2(3 H)$-Furanone & $97,68,125+55,84$ & u.i. +84 \\
\hline 8 & 16.47 & Pyrrole-2-carboxaldehyde & $95,94,66$ & 95 \\
\hline 9 & 16.72 & Unidentified & $97,68,43,56,139$ & u.i. \\
\hline 10 & 16.98 & $N$-Methyl- $N$-vinylacetamide & $56,57,99,43$ & 99 \\
\hline 11 & 18.45 & Acetamidoacetaldehyde & $43,73,72$ & 101 \\
\hline 12 & 18.75 & Unidentified & $85,56,43,127$ & u.i. \\
\hline 13 & 18.87 & 2-Pyrimidinamine & $95,68,41$ & 95 \\
\hline 14 & 19.72 & 2-(Acetoxymethyl)-pyridine & $108,107,92,43$ & 151 \\
\hline 15 & 19.94 & 4-Methoxybenzamine ( $p$-anisylamine) & $108,123,80,53$ & 123 \\
\hline 16 & 20.30 & Acetylpyridone (isomer 1) [29] & $109,95,81,68,137$ & 137 \\
\hline 17 & 20.83 & Acetylpyridone (isomer 2) [29] & $109,137,95,81,68$ & 137 \\
\hline 18 & 22.32 & 2-( $N$-methyl- $N$-ethylamino)phenol & $136,151,109$ & 151 \\
\hline 19 & 23.73 & 3-Acetamido-5-methylfuran & $97,69,139$ & 139 \\
\hline 20 & 24.02 & Unidentified & $83,125,54,55$ & u.i. \\
\hline 21 & 24.08 & 3-Acetamido-4-pyranone & $111,82,83,153$ & 153 \\
\hline 22 & 25.15 & $N$-Hydroxyphenylacetamide [29] & $109,80,81,151$ & 151 \\
\hline 23 & 26.61 & Unidentified & $43,79,122$ & u.i. \\
\hline 24 & 27.10 & Unidentified & $84,56,55,102$ & u.i. \\
\hline 25 & 28.64 & 3-Acetamido-6-methyl-4-pyranone & $125,167,43,69,97$ & 167 \\
\hline 26 & 29.19 & Unidentified & $84,55,83,125,167$ & u.i. \\
\hline 27 & 29.71 & $N$-3-pyridylacetamide & $94,136,67,43$ & 136 \\
\hline 28 & 32.24 & Dianhydro-2-acetamido-2-deoxyglucose [30] & $97,69,81,111,84$ & 185 \\
\hline 29 & 33.47 & 3-Acetamido-5-acetylfuran & $110,125,167,43$ & 167 \\
\hline 30 & 35.55 & Unidentified & $96,97,111,139$ & u.i. \\
\hline 31 & 36.30 & Unidentified & $72,114,43,156$ & u.i. \\
\hline 32 & 37.06 & Unidentified & $59,43,101,114$ & u.i. \\
\hline 33 & 37.57 & 1,6-Anhydro-2-acetamido-2-deoxyglucose [30] & $59,43,101,114$ & 203 \\
\hline 34 & 37.76 & Unidentified & $43,114,72,96,156$ & u.i. \\
\hline 35 & 38.60 & Unidentified & $101,43,59,143$ & u.i. \\
\hline 36 & 39.45 & Unidentified & $43,72,114,156,97$ & u.i. \\
\hline
\end{tabular}

u.i.: unidentified

macroscopic pyrolysis chars after 350 and $500{ }^{\circ} \mathrm{C}$ pyrolysis, respectively.

\section{Thermogravimetric analysis}

TGA experiments were carried out to characterize the thermal decomposition process of crab shell sample and to determine the temperatures suitable for the pyrolysis studies.
Figure 3a illustrates the thermogravimetric (TG) and derivative thermogravimetric (DTG) curves of crab shell biomass in argon atmosphere. The sample contained only minor amount of moisture $(0.4 \%)$, which evaporated between 50 and $150{ }^{\circ} \mathrm{C}$. The main decomposition process occurred in the temperature range $250-600{ }^{\circ} \mathrm{C}$ using $20{ }^{\circ} \mathrm{C} \mathrm{min} \mathrm{m}^{-1}$ heating rate. The initial mass loss and the shoulder on the DTG curve at about $320^{\circ} \mathrm{C}$ can be attributed to the cleavage 

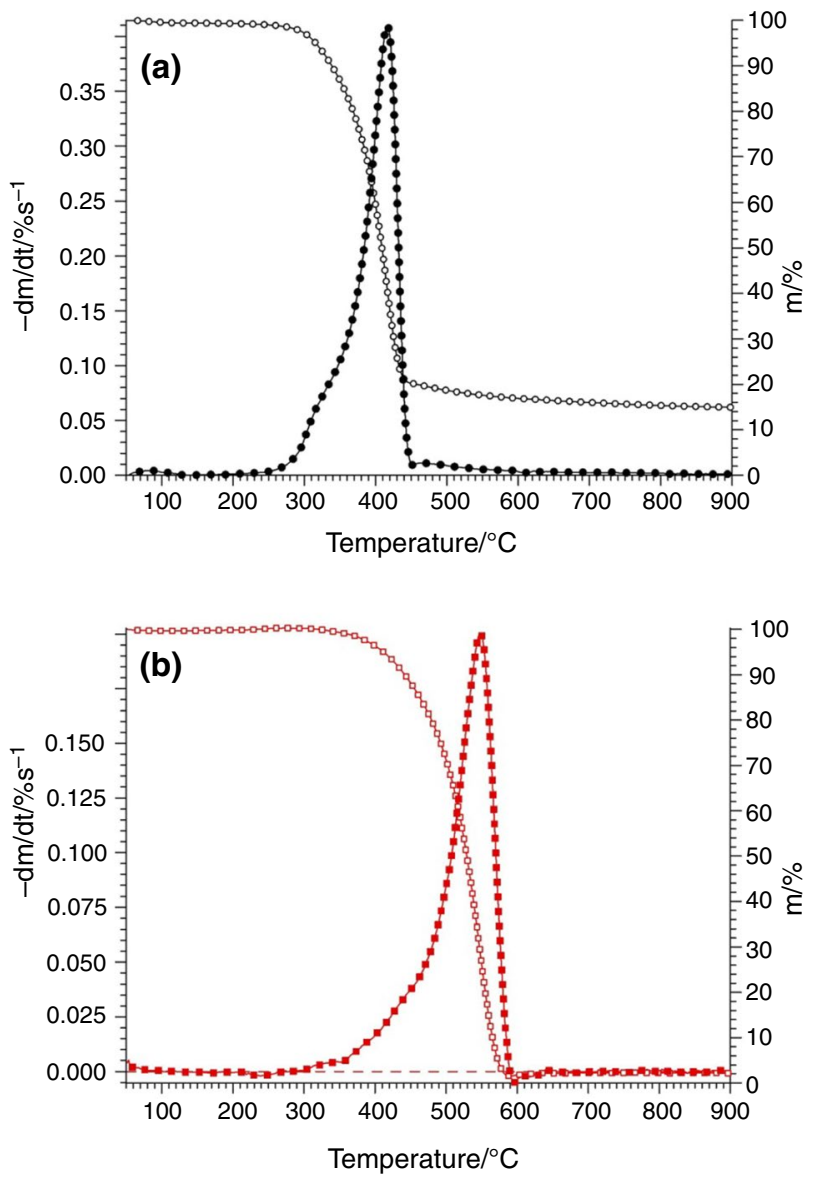

Fig. 3 (a) TG $(\bigcirc)$ and DTG $(\bullet)$ plots of crab shell biomass measured in inert (Ar) atmosphere, and (b) TG ( $\square$ ) and DTG (ם) plots of the carbonaceous residue of crab sample in synthetic air

of the hydroxyl and acetamide functional groups of $\mathrm{N}$-acetylglucosamine chains. The thermal decomposition reactions of polymer chains, mainly the depolymerization of chitin, are represented by the main peak of the DTG curve with the highest decomposition rate $\left(0.41 \% \mathrm{~s}^{-1}\right)$ at $417^{\circ} \mathrm{C}$. The thermal decomposition of the main part of crab sample ended at about $450{ }^{\circ} \mathrm{C}$. Above this temperature, only slow charring processes took place. The carbonaceous residue (char) of the sample was $18 \%$ at $500{ }^{\circ} \mathrm{C}$, and it reduced to $15 \%$ by $900{ }^{\circ} \mathrm{C}$, as can be seen on the TG curve shown in Fig. 3a.

After the thermogravimetric measurement, the argon atmosphere was substituted by synthetic air to burn the carbon content of the char (Fig. 3b). In oxidative atmosphere, the degradation of the char took place between 300 and $600{ }^{\circ} \mathrm{C}$ using $10{ }^{\circ} \mathrm{C} \mathrm{min}{ }^{-1}$ heating rate. The solid residue of the char was $1.8 \%$ at $900{ }^{\circ} \mathrm{C}$, so the ash content of the crab shell biomass was calculated to be around $0.3 \%$.

\section{Pyrolysis-gas chromatography/mass spectrometry}

For the better understanding of the whole char formation process, the release of volatile products from crab shell biomass was monitored by pyrolysis-gas chromatography/ mass spectrometry. As the DTG curve shows in Fig. 3a, the first decomposition event occurs at around $320^{\circ} \mathrm{C}$, and the main decomposition step terminates by about $500{ }^{\circ} \mathrm{C}$. On the basis of these data, the pyrolysis experiments were performed at $320^{\circ} \mathrm{C}$ and $500{ }^{\circ} \mathrm{C}$. It is noted that the lowertemperature macroscopic pyrolysis experiment was carried out at $350^{\circ} \mathrm{C}$ because the higher sample size required higher temperature to achieve similar decomposition level than in Py-GC/MS at $320^{\circ} \mathrm{C}$. The chromatograms of the volatile pyrolysis products (pyrograms) are illustrated in Fig. 4. The most intensive compounds are listed in Table 2.

The first group of unresolved compounds (peak \#1) in the chromatograms at low retention time (between 2.07 and $2.28 \mathrm{~min}$ ) corresponds to smaller molecular mass products and methyl iodide. The evolution of methyl iodide indicates the marine source of the crab. The smaller compounds represent mainly carbon dioxide, water and acetonitrile formed by the fragmentation of chitin, as well as a part of water is derived from the moisture content of the sample.

The main decomposition product originating from the crab shell biomass sample at $320^{\circ} \mathrm{C}$ pyrolysis temperature is the simplest amide, acetamide (peak \#5). The presence of acetamide indicates the scission of the $\mathrm{C}-\mathrm{N}$ bond between the polysaccharide chain and the acetamide side groups of chitin. The peak \#33 refers to the 1,6-anhydro-2-acetamido2-deoxyglucose, which is the main decomposition product of the chitin formed by depolymerization reaction pathway. The presence of peak \#33 in the first chromatogram indicates that the depolymerization of chitin has already started at $320^{\circ} \mathrm{C}$ (Fig. 4a).

The peak of acetic acid (peak \#3) can be found at lower retention time in the chromatogram of the crab shell biomass at $500{ }^{\circ} \mathrm{C}$ pyrolysis temperature. Acetic acid originates from the acetamide functional group of the chitin. The main decomposition products during the $500{ }^{\circ} \mathrm{C}$ pyrolysis process of crab shell are heterocyclic aromatic compounds (Fig. 4b). Oxygen-containing heterocyclic aromatic molecules (peaks $\# 19$, \#20, \#21 and \#25) originate from the glucose rings of chitin. Dianhydro-2-acetamido-2-deoxyglucose (peak \#28) is formed by dehydration reaction from 1,6-anhydro-2-acetamido-2-deoxyglucose (peak \#33) under severe pyrolysis condition.

Among the pyrolysis products, several heterocyclic aromatic rings contain one nitrogen atom (peaks \#6, \#8, \#14, \#16, \#17 and \#27). Some N-containing heterocycles are also released at lower temperature. Acetyl pyridone isomers (16 and 17) could be formed from the $\mathrm{N}$-acetylglucosamine unit by opening the sugar ring and 

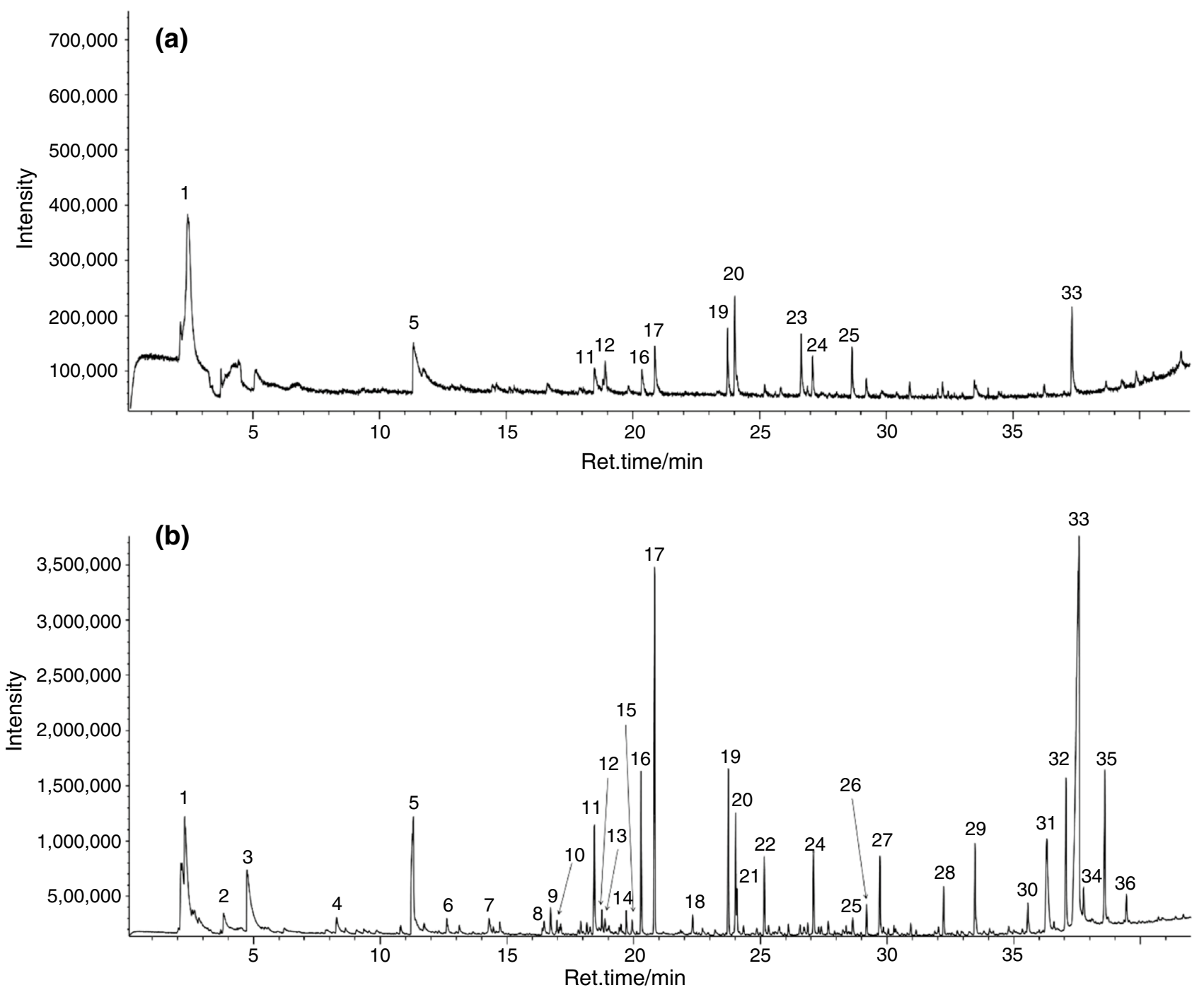

Fig. 4 Pyrograms of crab shell biomass pyrolyzed at $320^{\circ} \mathrm{C}$ (a) and $500{ }^{\circ} \mathrm{C}(\mathbf{b})$. Numbered peak identities are given in Table 2

replacing the ether group by an amido group. Beside the rearrangement, dehydration and decarboxylation reactions also take place leading to aromatic pyridone segments. Molecule of 2-pyrimidineamine (peak \#13) has two nitrogen atoms in the aromatic ring and one more in the amine functional group. The formation of this compound indicates that very profound bond scission and rearrangement reactions occur at a pyrolysis temperature of $500^{\circ} \mathrm{C}$. The evolution of $\mathrm{N}$-containing heterocycles proves the aromatization reactions during pyrolysis. XPS results show (Table 1) that the amount of $\mathrm{C}-\mathrm{N}=\mathrm{C}$ units increases in the char samples with increasing pyrolysis temperatures implying that the carbonaceous residue contains nitrogen atoms probably also in aromatic structures.

\section{Conclusions}

The main decomposition process of the crab shell investigated occurs at $300-500{ }^{\circ} \mathrm{C}$ in argon atmosphere resulting in about $18 \%$ char at $500{ }^{\circ} \mathrm{C}$ in the TGA experiment. The macroscopic pyrolysis leads to $24 \%$ char formation at $500{ }^{\circ} \mathrm{C}$. Considering the different conditions (samples size, heating rate and gas flow), the agreement is acceptable. The complex degradation mechanism of this biomass is reflected by the high number of volatile degradation species. The analysis of the volatile pyrolysis products demonstrates that acetamide groups start to be cleaved from the chitin chains at about $320^{\circ} \mathrm{C}$. Depolymerization of chitin polymer occurs already at $320{ }^{\circ} \mathrm{C}$ forming 1,6-anhydro-2-acetamido-2-deoxyglucose monomer and furan derivatives by dehydration. $\mathrm{N}$-containing heterocycles are also released at lower temperature $\left(320^{\circ} \mathrm{C}\right)$, but their formation becomes significant 
only at $500{ }^{\circ} \mathrm{C}$. XPS measurements of the precursor and two typical char samples show that the amount of $\mathrm{C}-\mathrm{NH}$ groups decreases, while that of $\mathrm{C}-\mathrm{N}=\mathrm{C}$ and $3 \mathrm{C}-\mathrm{N}$ increases during macroscopic pyrolysis. Assuming that the phosphorus content was unchanged during pyrolysis, the relative N/P intensity data indicate that 84 and $59 \%$ of the initial N-content is retained in the char after 350 and $500{ }^{\circ} \mathrm{C}$ pyrolysis, respectively.

Based on these results, the carbonaceous residue of the crab shell still contains a significant amount of nitrogen and is a potential support of transition metal catalysts. Other applications are also possible as referred to in the introduction. Nevertheless, during the biomass-to-carbon conversion special care has to be taken to prevent the release of the volatile components to the environment.

Acknowledgements Open access funding provided by Budapest University of Technology and Economics (BME). We thank Mr. Gy. Bosznai for his valuable technical assistance, Dr. J. Valyon's group for the elemental analysis, Mr. B. Pinke and Dr. L. Mészáros for SEM imaging (Department of Polymer Engineering, BME). Financial support from the VEKOP-2.3.2-16-2017-00013 is acknowledged. The VEKOP project is supported by the EU and by Hungary, co-financed by the European Regional Development Fund. The work is also part of the EU project NANOMED (H2020-MSCA-RISE-2016, \#734641), and PD 132438 and TNN 123499 projects financed by the National Research, Development and Innovation Office (NKFIH). The research reported in this paper was supported by the BME-Biotechnology FIKP grant of EMMI (BME FIKP-BIO).

Open Access This article is licensed under a Creative Commons Attribution 4.0 International License, which permits use, sharing, adaptation, distribution and reproduction in any medium or format, as long as you give appropriate credit to the original author(s) and the source, provide a link to the Creative Commons licence, and indicate if changes were made. The images or other third party material in this article are included in the article's Creative Commons licence, unless indicated otherwise in a credit line to the material. If material is not included in the article's Creative Commons licence and your intended use is not permitted by statutory regulation or exceeds the permitted use, you will need to obtain permission directly from the copyright holder. To view a copy of this licence, visit http://creativecommons.org/licenses/by/4.0/.

\section{References}

1. Titirici MM, White RJ, Falco C, Sevilla M. Black perspectives for a green future: hydrothermal carbons for environment protection and energy storage. Energy Environ Sci. 2012;5:6796-822.

2. Azwar E, Mahari WAW, Huang Chuah J, Vo DVN, Ma NL, Lam WH, Lam SS. Transformation of biomass into carbon nanofiber for supercapacitor application-a review. Int J Hydrog Energy. 2018;43:20811-21.

3. Yinon MB-O, Phillips R, Milo R. The biomass distribution on Earth. Proc Natl Acad USA. 2018;115:6506-11.

4. Bridgwater AV, Kuester JL. Research in thermochemical biomass conversion. London: Elsevier; 1988.

5. Meier D, Faix O. State of the art of applied fast pyrolysis of lignocellulosic materials-a review. Biores Technol. 1999;68:71-7.

6. Yan N, Chen X. Don't waste seafood waste. Nature. 2015;524:155-7.
7. Dahiya S, Tripathi RM, Hegde AG. Biosorption of lead and copper from aqueous solutions by pre-treated crab and arca shell biomass. Biores Technol. 2008;99:179-87.

8. Podust TV, Kulik TV, Palyanytsya BB, Gun'ko VM, Tóth A, Mikhalovska L, Menyhárd A, László K. Chitosan-nanosilica hybrid materials: preparation and properties. Appl Surf Sci. 2014;320:563-9.

9. Dabóczi M, Albert E, Agócs E, Kabai-Faix M, Hórvölgyi Z. Bilayered (silica-chitosan) coatings for studying dye release in aqueous media. The role of chitosan properties. Carbohydr Polym. 2016;136:137-45.

10. Rokhati N, Susanto H, Haryani K, Pramudono B. Enhanced enzymatic hydrolysis of chitosan by surfactant addition. Periodica Polytech Chem Eng. 2018;62:286-91.

11. Szabolcs Á, Molnár M, Dibó G, Mika LT. Microwave-assisted conversion of carbohydrates to levulinic acid: an essential step in biomass conversion. Green Chem. 2013;15:439-45.

12. Dai L, Zhu W, He L, Tan F, Zhu N, Zhou Q, He M, Hu G. Calcium-rich biochar from crab shell: an unexpected super adsorbent for dye removal. Biores Technol. 2018;267:510-6.

13. Shen F, Fu J, Zhang X, Qi X. Crab shell-derived lotus rootlike porous carbon for high efficiency isomerization of glucose to fructose under mild conditions. ACS Sustain Chem Eng. 2019;7:4466-72.

14. Park J-H, Wang JJ, Xiao R, Zhou B, Delaune RD, Seo D-C. Effect of pyrolysis temperature on phosphate adsorption characteristics and mechanisms of crawfish char. J Colloid Interface Sci. 2018;525:143-51.

15. Simsir H, Eltugral N, Karagoz S. Hydrothermal carbonization for the preparation of hydrochars from glucose, cellulose, chitin, chitosan and wood chips via low-temperature and their characterization. Biores Technol. 2017;246:82-7.

16. Uzoejinwa BB, He X, Wang S, Abomohra AEF, Hu Y, He Z, Wang Q. Co-pyrolysis of macroalgae and lignocellulosic biomass. Synergistic effect, optimization studies, modeling, and simulation of effects of co-pyrolysis parameters on yields. J Therm Anal Calorim. 2019;136:2001-16.

17. Wang S, Cao B, Feng Y, Sun C, Wang Q, Abomohra AEF, Afonaa-Mensah S, He Z, Zhang B, Qian L, Xu L. Co-pyrolysis and catalytic co-pyrolysis of Enteromorpha clathrate and rice husk. Toward high-quality products. J Therm Anal Calorim. 2019;135:2613-23.

18. Jakab E, Bora Á, Sebestyén Z, Borsa J. Thermal decomposition of chemically treated cellulosic fibers. J Therm Anal Calorim. 2018;132:433-43.

19. Várhegyi G, Wang L, Skreiberg Ø. Towards a meaningful non-isothermal kinetics for biomass materials and other complex organic samples. J Therm Anal Calorim. 2018;133:703-12.

20. Szúcs T, Szentannai P. Determining the mass-related reaction effectiveness factor of large, nonspherical fuel particles for bridging between intrinsic and apparent combustion kinetics. J Therm Anal Calorim. 2019;15:20-5. https://doi.org/10.1007/s10973-01909085-9.

21. Wang S, Jiang D, Cao B, Hu Y, Yuan C, Wang Q, He Z, Hui C-W, Abomohra AEF, Liu X, Feng Y, Zhang B. Study on the interaction effect of seaweed bio-coke and rice husk volatiles during co-pyrolysis. J Anal Appl Pyrol. 2018;132:111-22.

22. László K. Characterization and adsorption properties of polymer based microporous carbons with different surface chemistry. Microporous Mesoporous Mater. 2005;80:205-11.

23. Xiao B, Thomas KM. Adsorption of aqueous metal ions on oxygen and nitrogen functionalized nanoporous activated carbons. Langmuir. 2005;21:3892-902.

24. Nagy B, Bakos I, Bertóti I, Domán A, Menyhárd A, Mohai M, László K. Synergism of melamine and GO in the electrocatalytic 
behaviour of resorcinol - formaldehyde based carbon aerogels. Carbon. 2018;139:872-9.

25. Bertóti I, Mohai M, László K. Surface modification of graphene and HOPG by nitrogen plasma: quantitative XPS analysis of chemical state alterations. Carbon. 2015;84:185-96.

26. Gao Y, Zhang Y, Li A, Zhang L. Facile synthesis of high-surface area mesoporous biochar for energy storage via in-situ template strategy. Mater Lett. 2018;230:183-6.

27. Deschamps JR. Characterization of chitin preparations using powder and film X-ray diffraction methods. Powder Diffr. 2013;28(1):44-8.

28. László K, Bóta A, Dékány I. Effect of heat treatment on synthetic carbon precursors. Carbon. 2003;41:1205-14.
29. Furuhashi T, Beran A, Blazsó M, Czégény ZS, Schwarzinger C, Steiner G. Pyrolysis GC/MS and IR spectroscopy in chitin analysis of molluscan shells. Biosci Biotechnol Biochem. 2009;73:93-103.

30. van der Kaaden A, Boon JJ, de Leeuw JW, de Lange F, Schuyl PJW, Schulten H-R, Bahr U. Comparison of analytical pyrolysis techniques in the characterization of chitin. Anal Chem. 1984;56:2160-5.

Publisher's Note Springer Nature remains neutral with regard to jurisdictional claims in published maps and institutional affiliations. 